\title{
The Effect of Brand Equity on Brand Attitude and Brand Loyalty in Exhibition
}

\author{
Namju Shin ${ }^{1}$, Haelee $\mathrm{Kim}^{2}$, Sunah $\mathrm{Lim}^{3}$, Changsoo Kim ${ }^{4}$ \\ ${ }^{1}$ Tourism Chinese, Dongnam Health College, Suwon, Republic of Korea \\ ${ }^{2,3,4}$ Event and Convention Management, Graduate School, Kyonggi University, Seoul, Republic of \\ Korea
}

\begin{abstract}
The purpose of this study is to examine the influential relationships among exhibition brand equity, brand attitude and brand loyalty, focusing on the participants of 'HANATOUR International Travel Show' to evaluate brand equity and provide some helpful suggestions for the brand strategies of domestic exhibitions. Survey was conducted for three days from May 23, 2014 to May 25, 2014. The special range of study objects were collected with convenient sampling from the participants of HANATOUR International Travel Show in 2014. The data collected for this study were analyzed with the program AMOS 18.0. As a result, perceived quality and brand image as the components of brand equity had positive influence on brand attitude, brand attitude to brand loyalty, and brand awareness to brand loyalty. Therefore, the study concluded that 'HANATOUR International Travel Show' needs to try harder to establish brand equity and enhance their brand value to establish brand equity for a competitive and successful exhibition.
\end{abstract}

\section{Introduction}

Exhibition industry shows rapid and steady growth worldwide. According to the Global Association of the Exhibition Industry [1], in 2012, about 31,000 exhibitions were held, and about 260 million people participated in exhibitions. In particular, according to UFI's Exhibition World in 2014, Asian countries such as China and Korea keep growing in the field, and world's famous sponsors are expanding into Asian markets. As the global exhibition industries are developed, Korea has established the base for exhibition infrastructures which are essential for enlarging and globalizing the market by building the Exhibition Industry Development Act and by progressing The First Basic Plan (2008-2012).

The exhibition industry is a highly value-added service industry that has a huge influence on economic growth, income and employment, and nowadays, interest in the exhibition market is increasing as participants' purchase decision is increasingly influenced by the exhibition. According to the Center of Exhibition Industry Research (CEIR), $83 \%$ of the participants are influenced by the exhibition when they make a purchase, and about $90 \%$ of the participants are purchase decision makers [2]. Also, 91\% of information that influences on the purchase decision of exhibition purchasers is collected from the exhibitions [3]. 
There are many changes in domestic and international exhibition industry, such as the acceleration of world exhibition markets' dynamics and competitions, raise of importance of exhibitions following the increase of participants' purchase decision, and demands for specific exhibitions that satisfy various consumers. In order to adapt to these changes and keep developing, it is the most important to make exhibitions as a brand. Building brand power through distinctive brand images enables steady operation and development of exhibitions through stable profitability by leading participants' steady loyalty and by increasing market shares. Despite this importance, however, it is hard to find studies that focus on exhibitions as an independent brand equity.

The interest in travel began to increase from 2010. Especially the number of Korean tourists for overseas travel were 1,270,439 people, which increased by $4.0 \%$ compared with that in the same period of the previous year and they spent about $\$ 1,324$ [4]. Also the number of domestic travelers is about $37,800,004$ people which is about $87 \%$ among Korean people over 15 years old and their travel expense is about 232,343 billion won [5]. This continuous increase of travel business triggered extreme interest in travel exhibitions because they can be the most popular means for companies related to travel business. Thus, government organizations, local governments, associations, public companies and so on have been holding travel exhibitions competitively.

Competitions among these exhibitions may enhance the quality of the programs, but they may also damage the competitive edge of the programs due to a number of similar and duplicated exhibitions and may harm the brand images of present travel agencies. Therefore, making travel exhibitions as a brand can be a strong strategy for continuous development. The purpose of this study is to analyze the influential relationships among brand equity, brand attitude, and brand loyalty of travel exhibitions, based on participants of 'HANATOUR International Travel Show' since Hana Tour has the image of the top Korean travel company by keeping on winning the first place among Korean travel companies from 2004 and gaining the best brand value of BSTI (Brand Stock Top Index) in the second quarter of 2014 [6], and their participants have steadily increased since 2006. This study will offer helpful tips for the strategic operation of exhibition brand equity.

\section{Background}

\subsection{Brand Equity}

Farquhar [7] defines brand equity as the value added by a specific brand to a corporation or consumers, and Aaker [8] defines brand equity as a set of brand assets and brand liability related to a brand and its brand name and symbol, and it takes the role of increasing or decreasing the values that a product or a service offers to corporations and customers. Blackstone [9] defines a brand as a thing that has tangible and intangible value and features and a thing that results from the consumers' thoughts on products. Keller[10] defines a brand as a differentiated effect of brand knowledge whereby consumers react to marketing activities on the brand.

Aaker [8] proposed brand awareness, brand loyalty, perceived quality, brand association, and other properties form brand assets. Aaker and Joachimasthaler [11], Yoo and Donthu [12] classified brand awareness, brand loyalty, brand image, and perceived quality as brand equity's components, while Cobb-Walgren et al. [13] classified brand awareness, brand image, and perceived quality into brand equity. Based on the previous studies, this study defines exhibition brand equity as an overall value of a steady and distinctive brand recognized by exhibition participants, and adopts brand awareness, perceived quality and brand image as measurement factors. 


\subsection{Brand Attitude}

Brand attitude is the base of consumers' actions [10], and it is a consistent reaction in a favorable or unfavorable manner or learned tendency on a certain object[14]. Kotler et al. [15] defines brand attitude as a favorable or unfavorable personal evaluation, emotional feeling, and behavior tendency that an individual keeps. According to Mitchell and Olson [16] and Keller [17], brand attitude is a total or overall evaluation of consumers on a product that has a brand. Based on the previous studies, this study defines exhibition brand attitude as a learned tendency that exhibition participants have on a brand.

\subsection{Brand Loyalty}

Brand loyalty is the attachment that consumers have toward a certain brand $[8,18]$ and it means the favorable attitude and behavioral reaction that consumers have to a certain brand in a certain period [19]. Consumers maintain their preference for certain brands, and they depend on those brands when they purchase products [20], and they show favorable attitude toward certain brands by purchasing them continuously as time goes by [21]. Therefore, brand loyalty means the degree of immersion that makes consumers purchase their favored products or services repeatedly [18]. Based on the previous studies, this study defines exhibition brand loyalty as a favorable attitude toward an exhibition brand.

\section{Method}

\subsection{Research Model}

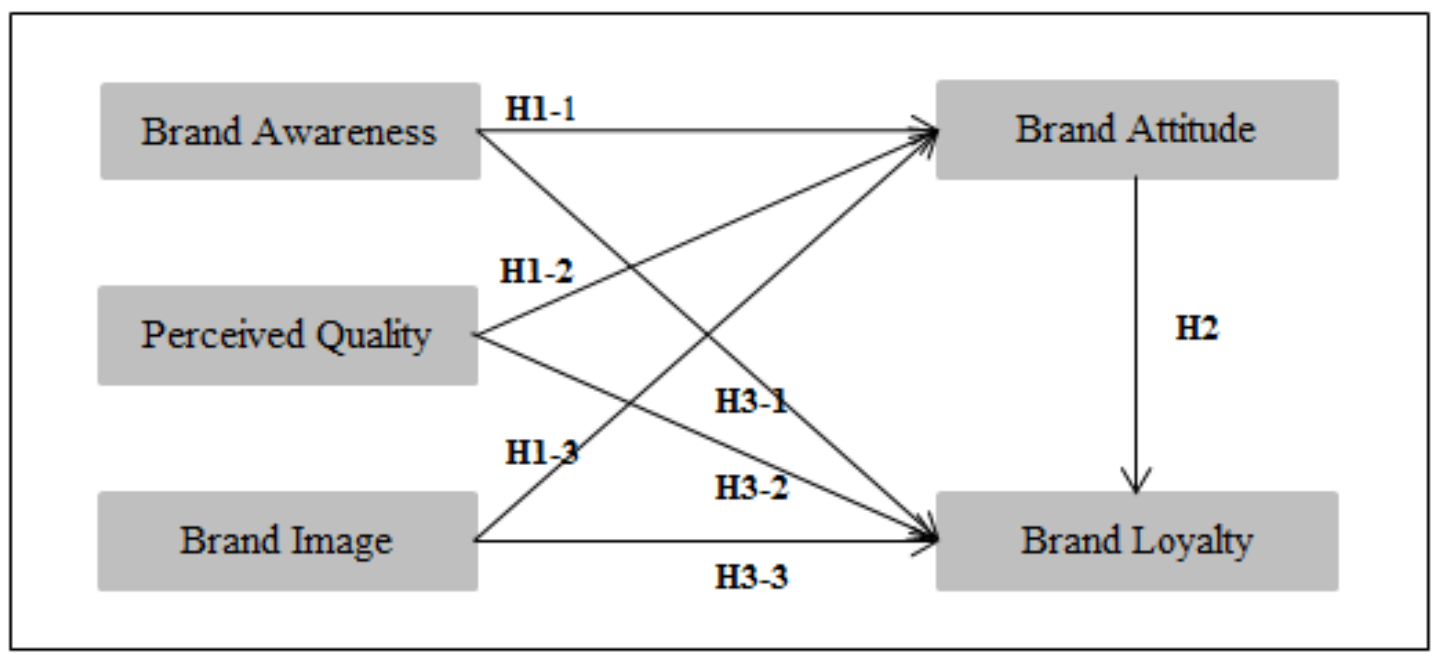

Figure 1. Research Model

\subsection{Research Hypotheses and Organization of the Survey}

Keller [10] found that brand association is a base of the attitude toward a brand, while Holiday [22] found that brand image is a factor that influences on the formation of brand attitude and the preference to a brand. Martinez, Montaner and Pina [23] also proved that brand image has a positive influence on expanded brand attitude. $\mathrm{Na}$, Marshall and Keller [24]'s study examined how brand awareness and brand image influence on brand attitude. Kwun and Oh [25]'s study introduced that brand awareness, 
brand image and perceived quality have positive influences on the attitude of corporate image. Based on the previous studies, this study proposes research hypotheses as follows.

\section{H1. Exhibition brand equity will have a positive influence to brand attitude. \\ H1-1. Exhibition brand awareness will have a positive influence to brand attitude. \\ H1-2. Exhibition perceived quality will give a positive influence to brand attitude. \\ H1-3. Exhibition brand image will have a positive influence to brand attitude.}

There have been several studies [26-27] that examined a positive relationship between brand attitude and brand loyalty. Based on the previous studies, this study proposes the following hypothesis.

\section{H2. Exhibition brand attitude will have a positive influence to brand loyalty.}

Through empirical studies, Shocker and Weitz [28] proved that brand loyalty is a parameter of brand equity. Through the study of the influence that a hotel brand equity has on customers' perceived value and loyalty, Kim, Bongran \& Kim [29] also explained that the brand equity has a positive influence. Thus, based on previous studies, this study proposes research hypotheses as follows.

\section{H3. Exhibition brand equity will have a positive influence to brand loyalty. \\ H3-1. Exhibition brand awareness will have a positive influence to brand loyalty. \\ H3-2. Exhibition perceived quality will have a positive influence to brand loyalty. \\ H3-3. Exhibition brand image will have a positive influence to brand loyalty.}

Based on the studies of Aaker [8], Keller [10, 17], Cobb-Walgren et al. [13], Yoo and Donthu [12], etc., the survey consists of 5 questions: each for brand awareness (e.g., I have heard of the brand), perceived quality (e.g., the program has high quality contents), and brand image (ex. it has a unique image), and 3 questions each for brand attitude (e.g.,. good), and brand loyalty (ex. I will participate again), in a 5 point scale.

\subsection{Research Method}

A survey was conducted for three days from May 23, 2014 to May 25, 2014. The study used convenience sampling from the participants of HANATOUR International Travel Show in 2014. 400 surveys were distributed and 342 questionnaires in total were collected, and after filtering 9 questionnaires that were blank or not proper to use, 333 questionnaires were selected as valid samples. The data collected for this study were analyzed by using the program AMOS 18.0.

\section{Results}

\subsection{General Characteristics of Respondents}

The number of female respondents was 198 (59.5\%), which was bigger than that of male respondents. As for age, 123 respondents were in their 20's (36.9\%); as for education level, 173 respondents were university graduates (52.0\%); as for their income level, 86 respondents were in the range of 2,000,000 KRW (25.8\%); as for occupation, there were 73 students $(21.9 \%)$ and 69 office workers $(20.7 \%)$. There were 159 respondents who answered no (47.7\%); as for the visit type, 140 respondents participated to the exhibition with friends/co-workers $(42.0 \%)$; as for the purpose of visit, 136 respondents visited to gather information $(40.8 \%)$, and the source that they gathered information the most from was the Internet, which counted 110 respondents $(33.0 \%)$. 


\subsection{Reliability and Factor Analysis}

Confirmatory factor analysis was conducted to test reliability, RMR was 0.053 ; GFI(0.929), NFI(0.945), CFI(0.972), IFI(0.972) were over 0.9; AGFI was also 0.898 which shows the suitability of the study model. Variables with SMC under 0.4 were deleted, which were two from brand awareness and one from perceived quality. All the factor loadings, standardized with $\mathrm{p}=0.000$, were significant with $99 \%$ confidence level, and in most paths, standardized regression weights were over 0.6 , which is statistically significant.

\subsection{Correlation Analysis}

All the variables were correlated with significance level under 0.01, and among brand awareness, perceived quality, brand image, brand attitude, and brand loyalty, all the correlations showed positive relationships. In addition, AVE and CR values were over 0.5 and 0.7 , respectively, which ensures the validity.

\subsection{Model fit and Hypothesis tests}

GFI, AGFI, NFI, CFI, IFI, etc. show favorable values, compared with the standard and RMR is 0.053 , which indicates the model is suitable for hypotheses test.

Table 1. The Results of Hypothesis Tests

\begin{tabular}{|c|c|c|c|c|c|c|}
\hline \multirow[b]{2}{*}{ Hypotheses } & \multicolumn{2}{|c|}{ Estimate } & \multirow[b]{2}{*}{ S.E. } & \multirow[b]{2}{*}{ C.R. } & \multirow[b]{2}{*}{$\mathrm{P}$} & \multirow[b]{2}{*}{ Results } \\
\hline & $\begin{array}{l}\text { Non- } \\
\text { STD }\end{array}$ & STD & & & & \\
\hline $\begin{array}{l}\text { Brand awareness will have a positive } \\
\text { influence on brand attitude (H1-1). }\end{array}$ & 0.031 & 0.044 & 0.034 & 0.917 & 0.359 & Rejected \\
\hline $\begin{array}{l}\text { Perceived quality will have a positive } \\
\text { influence on brand attitude (H1-2). }\end{array}$ & 0.387 & 0.350 & 0.100 & 3.867 & 0.000 & Accepted \\
\hline $\begin{array}{l}\text { Brand image will have a positive } \\
\text { influence on brand attitude ( } \mathrm{H} 1-3) \text {. }\end{array}$ & 0.573 & 0.457 & 0.121 & 4.741 & 0.000 & Accepted \\
\hline $\begin{array}{l}\text { Exhibition brand attitude will have a } \\
\text { positive influence on brand loyalty.(H2) }\end{array}$ & 0.894 & 0.839 & 0.083 & 10.799 & 0.000 & Accepted \\
\hline $\begin{array}{l}\text { Brand awareness will have a positive } \\
\text { influence on brand loyalty (H3-1). }\end{array}$ & 0.144 & 0.193 & 0.033 & 4.373 & 0.000 & Accepted \\
\hline $\begin{array}{l}\text { Perceived quality will have a positive } \\
\text { influence on brand loyalty (H3-2). }\end{array}$ & 0.009 & 0.007 & 0.093 & 0.092 & 0.926 & Rejected \\
\hline $\begin{array}{l}\text { Brand image will have a positive } \\
\text { influence on brand loyalty }(\mathrm{H} 3-3) \text {. }\end{array}$ & -0.102 & -0.076 & 0.116 & -0.878 & 0.380 & Rejected \\
\hline
\end{tabular}

As a result of this study, H1-2, H1-3, H2, and H3-1 were accepted with positive influence, but H1-1, H3-2, H3-3 were rejected. According to the result of H1, brand awareness was a prerequisite for perceived quality and brand image, but there was no significant relationship between brand awareness 
and attitude toward Hanatour Travel Show. This may result from the lack of brand awareness due to the short history of the exhibition. According to the result of H3, perceived quality and image of the brand, Hanatour Travel Exhibition, have low influential power to increase the brand loyalty of participants; this may be influenced by the participants' confusion and misuse of brand images between 'Hanatour' and 'HANATOUR International Travel Show' .

\section{Conclusion}

The purpose of this study is to examine the influential relationships among exhibition brand equity, brand attitude and brand loyalty, focusing on the participants of 'HANATOUR International Travel Show'. Results reveal the current brand equity (except for brand awareness) of HANATOUR International Travel Show did not show a statistical significant effect on brand loyalty, but at the same time, the result indicates that the international exhibition needs to try harder in order to establish brand equity for the uniqueness of the exhibition and to enhance their brand value.

Based on results, this study suggests several practical implications for successful exhibition.

First, it is strongly recommended to find various ways how the exhibition can satisfy participants' general characteristics and their needs and expectation. It is urgent to develop exhibit marketing strategy not only to increase loyalty of current participants, but also to attract new participants.

Second, it is necessary to implement active advertising strategies in order to enhance awareness and build a differentiated brand image. Possibly they can boost advertising through the Internet, SNS, etc., and issue invitation cards to original participants, and it is also recommended to develop logos, commercial music, symbols like characters and slogans that can symbolize the exhibition and they should use them effectively.

Third, the most important thing is to improve the service environment in order to increase the perceived quality of the exhibition. This includes the improvement of the actual environment, the creation of corporate culture which focuses on customers, and service education for employees. In addition, it is necessary to develop various services and programs to raise the level of participants' satisfaction.

Lastly, general participants show interest in products that are lower in price than other products, while high-loyalty participants are interested in product details and explanations. Thus, it is necessary to find out how to lead the participants to on-site reservation sales.

This study is limited in that it focuses only on the participants in the exhibition. Therefore, for future research, it will be useful to examine participating exhibitors. In addition, the current study will gain more reliability if it is possible to compare similar travel exhibitions through the same research methodology.

\section{References}

1. UFI, The Global Exhibition Industry statistics 2014 (2014)

2. GFAIRKOREA, The Reason Why Exhibition should be the mean of Marketing, G-FAIR LIFE (2014. 5. 9)

3. Y. H. Roh, Study on the satisfaction and the determined factors of activities intended for industrial trade shows, Seoul: Kyonggi University (2005)

4. $\quad$ Korea Culture \& Tourism Institute, Analysis of Traveling Trend (2014.6)

5. Korea Culture \& Tourism Institute, WEBZINE for Culturing Traveling (2014.7)

6. Yonhap News (2014.7.24)

7. P. H. Farquhar, MR, 1, 9, 24-33(1989)

8. D. A. Aaker, Managing Brand Equity Capitalizing on the Value of a Brand Name, New York: Free Press (1991)

9. M. Blackstone, Beyond Brand Personality: Building Brand Relationships, Brand Equity and 
Advertising: Advertising's Role in Building Strong Brand, New York: Psychology Press (1993)

10. K. L. Keller, JOM, 57, 1, 1-22 (1993)

11. D. A. Aaker, E. Joachimasthaler, Brand Leadership, New York: Free Press (2000)

12. B. Yoo, N. Donthu, JOBR, 52, 1, 1-14 (2001)

13. C. J. Cobb-Walgren, C. A. Ruble, N. Donthu, 1995, JOA, 24, 3, 25-40 (1995)

14. M. Fishbein, I. Ajzen, Belief, Attitude, Intention and Behavior: An Introduction to Theory and Research, Reading, MA: Addison-Wesley Publishing Company (1975)

15. P. Kotler, J. T. Bowen, J. C. Makens, Marketing for Hospitality and Tourism, NJ: Prentice Hall (1999)

16. A. A. Mitchell, J. C. Olson, A\&SR 1, issue 1 (2000)

17. K. L. Keller, Strategic Brand Management: Building, Measuring and Managing Brand Equity, NJ: Prentice Hall (2002)

18. R. L. Oliver, JOM, 63, special issue, 33-44 (1999)

19. J. F. Engel, R. D. Blackwell, Consumer Behavior, Fourth Edition, Chicago: The Dryden Press (1982)

20. S. W. Brown, E. Gummesson, B. Edvardsson, B. Gustavsson, Service Quality: Multidisciplinary and Multinational Perspectives, New York: Lexington Books (1991)

21. H. Assael, Consumer Behavior: A Strategic Approach, New York: Houghton Mifflin (2003)

22. J. Holiday, AA, 3, 342-357 (1996)

23. E. Martinez, T. Montaner, J. M. Pina, JOBR, 62, 3, 305-313 (2009)

24. W. B. Na, R. Marshall, K. L. Keller, Measuring Brand Power: Validating a Model for Optimizing Brand Equity, JOPABM, 8, 170-184 (1999)

25. D. J. W. Kwun, H. Oh, IJOHM, 26, 1 , 81-97 (2007)

26. S. B. MacKenzie, R. J. Lutz, G. E. Belch, JOM, 23, 2 , 130-143 (1986)

27. P. N. Shamdasani, A. A. Balakrishnan, APJOM, 17, 3 , 399-422 (2000)

28. A. D. Shocker, B. Weitz, A Perspective on Brand Equity Principles and Issues, In Defining, Measuring and Managing Brand Equity, Conference Summary (Report No. 88-104), Marketing Science Institute, Cambridge, MA. (1988)

29. W. G. Kim, J. S. Bongran, H. J. Kim, JOHATR, 32, 2 , 235-254 (2008) 